\title{
Nonresonant EFISH and THG studies of nonlinear optical property and molecular structure relations of benzene, stilbene, and other arene derivatives
}

\section{Citation for published version (APA):}

Cheng, L. T., Tam, W., Meredith, G. R., Rikken, G. L. J. A., \& Meijer, E. W. (1990). Nonresonant EFISH and THG studies of nonlinear optical property and molecular structure relations of benzene, stilbene, and other arene derivatives. In G. Khanarian (Ed.), Nonlinear Optical Properties of Organic Materials II, 1989, San Diego (pp. 6172). (Proceedings of SPIE; Vol. 1147). SPIE. https://doi.org/10.1117/12.962108

DOI:

$10.1117 / 12.962108$

Document status and date:

Published: 01/01/1990

\section{Document Version:}

Publisher's PDF, also known as Version of Record (includes final page, issue and volume numbers)

\section{Please check the document version of this publication:}

- A submitted manuscript is the version of the article upon submission and before peer-review. There can be important differences between the submitted version and the official published version of record. People interested in the research are advised to contact the author for the final version of the publication, or visit the DOI to the publisher's website.

- The final author version and the galley proof are versions of the publication after peer review.

- The final published version features the final layout of the paper including the volume, issue and page numbers.

Link to publication

\footnotetext{
General rights

- You may freely distribute the URL identifying the publication in the public portal. follow below link for the End User Agreement:

www.tue.nl/taverne

\section{Take down policy}

If you believe that this document breaches copyright please contact us at:

openaccess@tue.nl

providing details and we will investigate your claim.
}

Copyright and moral rights for the publications made accessible in the public portal are retained by the authors and/or other copyright owners and it is a condition of accessing publications that users recognise and abide by the legal requirements associated with these rights.

- Users may download and print one copy of any publication from the public portal for the purpose of private study or research.

- You may not further distribute the material or use it for any profit-making activity or commercial gain

If the publication is distributed under the terms of Article $25 \mathrm{fa}$ of the Dutch Copyright Act, indicated by the "Taverne" license above, please 


\title{
Nonresonant EFISH and THG Studies of Nonlinear Optical Property and Molecular Structure Relations of Benzene, Stilbene, and other Arene Derivatives.
}

\author{
L.-T. Cheng, W. Tam, and G. R. Meredith \\ Central Research and Development Department, E. I. Du Pont De Nemours \& Co., Inc., Experimental Station, \\ P.O. Box 80356, Wilmington, Delaware 19880-0356 \\ G. L. J. A. Rikken and E. W. Meijer
}

Philips Research Laboratories, P. O. Box 80.000, 5600 JA Eindhoven, the Netherlands

\begin{abstract}
We report D. C. electric field induced second harmonic generation (EFISH) and third harmonic generation (THG) measurement results on the intrinsic molecular hyperpolarizabilities of benzenes, stilbenes, and other arene derivatives. Structure-property relations, as revealed by a comprehensive set of systematic measurements, are discussed. Issues concerning donor-acceptor strength; charge-transfer; transparency trade-off; conjugation planarity, length, and aromaticity; and heteroatom and side-group substitution effects are included.
\end{abstract}

\section{INTRODUCTION}

Despite intense interest, few verified guidelines for the design of optically nonlinear molecules have appeared since the early recognition of the importance of charge-transfer excitations. Our general objectives are to develop detailed understanding of structural factors that govern molecular nonlinear polarization mechanisms and to engineer, based on this knowledge, optimized structures for various applications. We have taken an experimental approach. Relying on well-designed techniques, such as electric field induced second harmonic generation (EFISH) and third harmonic generation (THG), and the availability of materials and synthetic collaborations, we have systematically characterized the linear and nonlinear molecular polarizabilities of a diversity of promising structures.

Many of the molecules included here have been characterized before, often repeatedly by different workers in this field. However, as a result of differing experimental and theoretical methodologies such as laser freqencies, solvents, local field models, and data reduction schemes, widely differing results have been reported ${ }^{1}$. It becomes quite difficult to draw conclusions concerning the finer points of molecular hyperpolarizability from such a collection of data. We have developed a relatively efficient and acurate experimental technique to study molecular nonlinearity in solutions. Details of the experimental setup and calibration will be given elsewhere ${ }^{2}$. Our intention is to carry out systematic measurements and obtain internally consistent data so that conclusions can be drawn concerning the structural factors which influence optical nonlinearity. Based on results obtained on benzene, stilbene, and other arene derivatives, some of these structural factors are discussed.

\section{EXPERIMENTAL CONSIDERATIONS}

To extract the molecular hyperpolarizability $\beta$, a lengthy set of physical and optical measurements need to be carried out. These include, on a series of solutions with graded concentrations, measurement of density, refractive index at several wavelengths, capacitance, THG, and EFISH amplitudes and coherence lengths. These measurements respectively determine the specific volume of a solute molecule in solution, solution dispersion, solution dielectric properties, and the THG and EFISH nonlinear susceptibilities for each solution. With the exception of the THG and EFISH measurements, of which a brief description of the experimental configuration will be given, all other measurements are 
performed according to well established procedures. With the measured solution properties, following the full Onsager local field model ${ }^{3}$ and taking the infinite dilution limit ${ }^{4}$, the relevant molecular properties including the dipole moment, $\mu$, the low frequency linear polarizabilty, $\alpha$, the hyperpolarizability, $\beta$, and the second hyperpolarizability, $\gamma$, can be calculated. In addition, absorption spectra are collected for most molecules in p-dioxane or cyclohexane solutions, and solvatochromic measurements are carried out to assess the charge-transfer nature of the low lying electronic excitations of a selected set of para disubstituted benzene and stilbene derivatives.

The experimental setup for the EFISH and THG experiments is shown in Fig. (1). It consists of a $20 \mathrm{~Hz} \mathrm{Nd:YAG} \mathrm{laser}$ with $10 \mathrm{~ns}$ pulses of $0.4 \mathrm{~J}$ in energy. The $1.06 \mu \mathrm{m}$ output pumps a hydrogen Raman shifter, providing up to $120 \mathrm{~mW}$ of Stokes radiation at $1.91 \mu \mathrm{m}$. The Stokes radiation serves as the fundamental frequency for both the EFISH and THG experiment with the harmonic wavelengths at $954 \mathrm{~nm}$ and $636 \mathrm{~nm}$ respectively. For most lightly colored compounds with absorption edges below $500 \mathrm{~nm}$, the measurement can be considered as truely nonresonant. THG and EFISH experiments are carried out with an unconventional technique in which the harmonic amplitudes and coherence lengths are measured separately. The goal is to eliminate possible environmental contributions, which are known to be important in THG and, to a lesser extent, EFISH measurements 5,6 , and to increase the measurement precision by eliminating the necessity of simultaneously extracting several parameters from data fitting as is the case for the conventional Maker's fringe or wedge techniques. The laser beam is divided three ways for an intensity normalization reference channel, the coherence length measurements, and the amplitude measurements. The second and third harmonic signals are separated with dichroic mirrors.

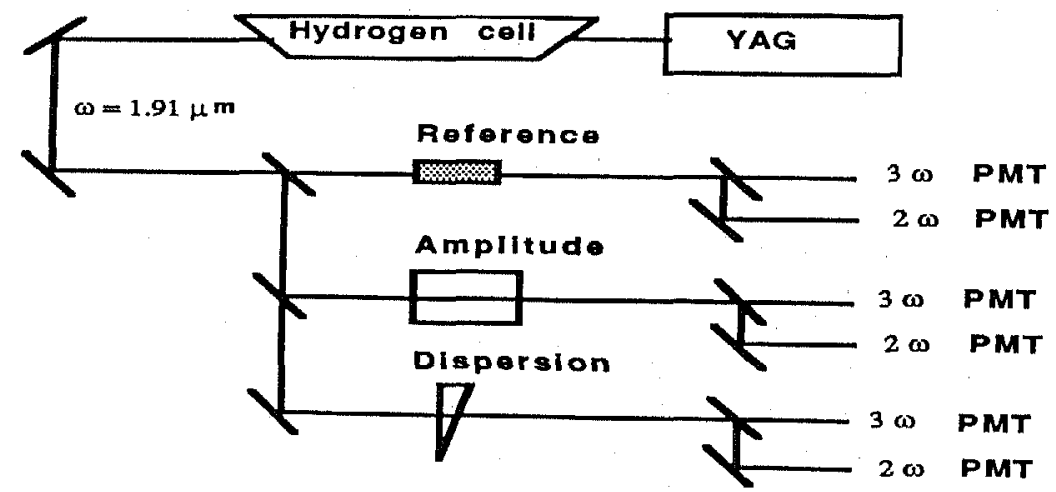

Figure 1. Schematic of optical setup

For the determination of harmonic amplitudes, a tight focusing geometry and a "single interface" sample cell with adjacent chambers are used. To achieve the situation of Gaussian propagation of a tightly focused laser beam across a single interface, the sample cell has a $2 \mathrm{~cm}$ thick front window and a long liquid path length such that harmonic generations from the outer two interfaces of the cell and air can be ignored due to the rapid beam divergence. Gold concurrently. With the interface window-liquid interface so that both THG and EFISH measurements can be carried out continuity relations of electromagnetic fields at the interface andia placed at the focal region, it can be shown, from harmonic generated by a focused Gaussian beam, that the and the $(n-1) \pi$ phase shift between the far fields of the nth nonlinearity difference of the two media. In the case of $T$ non-phase-matched harmonic intensity is a measure of the

$$
I^{1 / 2}(3 \omega) \propto\left(\frac{u_{g l} \chi_{g}^{3} l_{g}}{n_{g}^{\omega}+n_{g}^{3 \omega}}-\frac{v_{g l} \chi_{1}^{3} l_{1}}{n_{1}^{\omega}+n_{1}^{3 \omega}} t_{g l}^{3}\right) E^{3}(\omega)
$$

where $\chi_{g}^{3}, l_{g}, \chi^{3}$, and $1_{1}$ are the third order nonlinear susceptibilities and coherence lengths of the window material and the liquid respectively. Other symbols in Eqn.(1) are transmission factors determined by the various refractive indexes. Comparative measurements are performed by translating the sample solution chamber and the 
reference liquid chamber sequentially into the optical path. The ratio of the harmonic intensities generated from the two chambers are recorded. The coherence lengths for the harmonic generations are determined with a wedged liquid cell consisting of crystalline quartz windows, which generate sufficient second and third harmonic radiations for easy measurement. The oscillatory second and third harmonic signals are fitted to yield the coherence lengths. With the known THG and EFISH nonlinerities and coherence lengths of the window material and the reference liquid ( BK7-grade A glass: $\chi^{3} \mathrm{THG}=4.7 \times 10^{-14} \mathrm{esu}, 1_{\mathrm{THG}}=16.7 \mu \mathrm{m}, \chi^{3} \mathrm{EFISH}=3.5 \times 10^{-14} \mathrm{esu}$, and $1_{\mathrm{EFISH}}=38.8 \mu \mathrm{m}$; toluene: $\chi^{3}{ }_{\mathrm{THG}}=9.9 \times 10^{-14} \mathrm{esu}, \mathrm{l}_{\mathrm{THG}}=18.3 \mu \mathrm{m}, \chi^{3} \mathrm{EFISH}=9.1 \times 10^{-14} \mathrm{esu}$, and $\left.\mathrm{l}_{\mathrm{EFISH}}=73.5 \mu \mathrm{m}\right)^{2,7}$ as well as the coherence lengths of the sample solution, the solution nonlinear susceptibilities can be computed.

All relevant molecular properties are calculated according to the Onsager local field model for both static and optical fields and taking the infinite dilution limit for all concentration dependent quantities. The effective refractive indexes for the solute molecule in solution, as required by the Onsager model, are deduced from the solute specific volume and high frequency polarizabilities. The vectorial component, $\beta$, of the molecular hyperpolarizbility tensor along the dipole moment is calculated according to

$$
\gamma^{\mathrm{EFISH}}=\gamma^{\mathrm{e}}+\gamma^{\mathrm{v}}+\frac{\mu \beta}{5 \mathrm{kT}}
$$

where $\gamma^{\hat{e}}+\gamma^{\mathrm{v}}$, denoting the electronic and deformational contributions, is assumed to be proportional to $\gamma^{\mathrm{THG}}$. The proportionality constant, with typical values between 0.7 and 0.8 , is determined by measurements of centrosymmetric molecules with structure similar to that of the nonlinear molecule in question. For moderately nonlinear molecules with comparable transition energies, such a procedure is likely to be adequate to compensate for the different frequency dependences of the two $\gamma \mathrm{s}$. For high $\beta$ molecules in highly polar or polarizable solvents, second order local field cascading effects will lead to artificially large third order responses 7 . The measurement of $\gamma^{\mathrm{THG}}$ provides an estimate of the cascade contribution to $\gamma \mathrm{EFISH}$. The accuracy of such an estimate however is unchecked, particularly when different solvents are used. For this and other reasons, we carry out our measurements in the same solvent (p-dioxane for its dissolving power, low polarizability, and zero dipole moment) whenever possible and avoid using highly polar solvents.

\section{RESULTS AND DISCUSSION}

\section{Donor Acceptor Strengths}

To achieve asymmetric polarizability, organic chemists rely on the familiar electron donating or accepting properties of chemical groups to induce charge asymmetry on various conjugated structures whose delocalized $\pi$ electrons are most susceptible to such substituent influence. To evaluate the electronic biasing strength of various donor and acceptor groups, we begin our studies of molecular hyperpolarizability on monosubstituted benzene derivatives. A wide range of electron donating and withdrawing substituents are examined including the less conventional thioalcohol, thiomethyl, nitroso, and dicyanovinyl groups. Measurement results are tabulated in Table 1. The most striking observation is that with the exception of dimethylamine, all the donors are found to be ineffective in inducing charge asymmetry. This can be seen from the small dipole moments and $\beta$ values of the donor substituted benzenes. Even for anisole and thioanisole, their hyperpolarizabilities are too small to be determined by the accuracy of the current theoretical model. Although their $\gamma^{\mathrm{EFISH}}$ and $\gamma^{\mathrm{THG}}$ can be accurately determined (within the Onsager local field model), without performing temperature dependent studies, separation between the electronic and dipolar contributions to EFISH remains somewhat ambiguous. For centric molecules such as benzene, $\mathrm{p}$-dioxane and $\mathrm{p}$-xylene, the ratio between $\gamma^{\mathrm{EFISH}}$ and $\gamma^{\mathrm{THG}}$ is around 0.8 , which has been used as a cride estimate of the electronic and deformational contributions to EFISH signal for benzene derivatives. Examination of the $\gamma^{\mathrm{EFISH}}$ and $\gamma^{\mathrm{THG}}$ values in Table 1 reveals that for donor substituted benzenes, both values change in parallel indicating a small dipolar contribution to EFISH signal. This is partly due to the small dipole moments. Similar situation is found for the halogen derivatives. Clearly, neglecting the electronic and deformational contributions to EFISH will give erroneous results. 
The ineffectiveness may be attributed to two factors. Other than the dimethylamino group, the connecting atom in all the donors, including the amino, is $\mathrm{sp}^{3}$ hybridized. The tetrahedral geometry does not allow efficient overlap between the lone pair containing donor orbitals and the $\pi$ orbitals of the benzene ring. In addition, these donor substitutions only result in minimal extensions of the benzene conjugation. Accepting groups are found to be much more effective, with $\mathrm{CN}, \mathrm{COH}, \mathrm{NO}, \mathrm{NO}_{2}$, and $\mathrm{CHC}(\mathrm{CN})_{2}$ groups in increasing order $\left(\mathrm{C}_{2}(\mathrm{CN})_{3}\right.$ is significantly better than $\mathrm{CHC}(\mathrm{CN})_{2}$ as revealed from studies of disubstituted benzenes discussed below). Nitroso is found to be comparable to nitro while aldehyde is much superior to the cyano group in leading to asymmetric polarizability. The proper hybridizations and longer extensions of the benzene conjugation may be reasons for the effectiveness of the accepting groups. This view is supported by the large $\beta$ of benzylidene malonitrile and its extended structure.

Table 1: Results on Monosubstituted Benzenes.

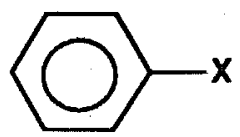
$\mathrm{X} \quad \gamma_{\mathrm{EFISH}} 10^{-36}$
$\gamma_{\text {THG }} 10^{-36}$
$\gamma_{\text {EFISH }} / \gamma_{\text {THG }}$
$\mu 10^{-18}$
$\alpha 10^{-23}$
$\beta 10^{-30}$ (esu)

\begin{tabular}{cllllll}
\hline $\mathrm{H}$ & 3.1 & 3.9 & 0.80 & 0.0 & 1.1 & 0.0 \\
p-Dioxane & 1.9 & 2.5 & 0.76 & 0.0 & 0.9 & 0.0 \\
P-Xylene & 4.3 & 5.2 & 0.83 & 0.0 & 1.5 & 0.0 \\
$\mathrm{CH}_{3}$ & 4.1 & 4.6 & 0.88 & 0.38 & 1.3 & $<0.2$ \\
$\mathrm{OH}$ & 4.0 & 5.0 & 0.80 & 1.5 & 1.2 & $<0.2$ \\
$\mathrm{SH}$ & 4.6 & 6.3 & 0.73 & 1.4 & 1.5 & $<0.2$ \\
$\mathrm{OMe}$ & 3.8 & 4.8 & 0.79 & 1.4 & 1.4 & $<0.2$ \\
$\mathrm{SMe}$ & 5.9 & 7.2 & 0.82 & 1.3 & 1.7 & $<0.2$ \\
$\mathrm{NH}_{2}$ & 7.8 & 5.4 & 1.45 & 1.5 & 1.3 & 0.55 \\
$\mathrm{NMe}_{2}$ & 14.1 & 8.1 & 1.70 & 1.6 & 1.7 & 1.1 \\
$\mathrm{~F}$ & 2.2 & 3.5 & 0.63 & 1.5 & 1.1 & $<0.2$ \\
$\mathrm{Cl}$ & 2.0 & 4.5 & 0.44 & 1.6 & 1.3 & $<0.2$ \\
$\mathrm{Br}$ & 4.4 & 5.4 & 0.81 & 1.4 & 1.4 & $<0.2$ \\
$\mathrm{I}$ & 7.2 & 7.5 & 0.96 & 1.3 & 1.7 & $<0.2$ \\
$\mathrm{CN}$ & 10.3 & 4.3 & 2.4 & 3.9 & 1.3 & 0.36 \\
$\mathrm{COH}$ & 14.8 & 5.3 & 2.8 & 2.8 & 1.3 & 0.80 \\
$\mathrm{NO}$ & 30.0 & 6.8 & 4.4 & 3.1 & 1.4 & 1.7 \\
$\mathrm{NO}{ }_{2}$ & 40.8 & 5.7 & 7.2 & 4.0 & 1.4 & 1.9 \\
$\mathrm{C}_{2} \mathrm{H}(\mathrm{CN})_{2}$ & 82.3 & 12 & 6.9 & 4.8 & 2.0 & 3.1 \\
\hline
\end{tabular}

\section{Charge Transfer and Transparency Trade-off}

The cooperative effects of donor and acceptor groups are investigated by studying disubstituted benzene derivatives. Some of the measurement results are given in Table 2 and 3. For para disubstituted derivatives, a significant increase in $\beta$ over the sum of the monosubstituted fractments is observed. This is the well recognized enhancement resulting for instance, the charge-transfer effectiveness of various donors can be established given acceptor, the nitro group $\mathrm{SMe}, \mathrm{N}_{2} \mathrm{H}_{3}, \mathrm{NH}_{2}$, and $\mathrm{NMe}_{2}$ in increasing order. From measurements on tricyanovinyl derivatives, the bridged julolidine is the strongest donor found in the present studies. The ordering among acceptors remains unchanged as 
Table 2: Results on disubstituted nitrobenzenes.

\begin{tabular}{|c|c|c|c|c|c|c|c|}
\hline$X$ & $\mathrm{Y}$ & solvent & $\lambda_{\max }$ & $\mu 10^{-18}$ & $\alpha 10^{-23}$ & $\beta 10^{-30}$ & $\gamma 10^{-36}(e s u)$ \\
\hline \multicolumn{8}{|l|}{ Para- } \\
\hline $\mathrm{NO}_{2}$ & $\mathrm{Me}$ & p-Diox & 272 & 4.2 & 1.6 & 2.1 & 8 \\
\hline $\mathrm{NO}_{2}$ & $\mathrm{Br}$ & p-Diox & 274 & 3.0 & 1.8 & 3.3 & -- \\
\hline $\mathrm{NO}_{2}$ & $\mathrm{OH}$ & p-Diox & 304 & 5.0 & 1.5 & 3.0 & 8 \\
\hline $\mathrm{NO}_{2}$ & OPh & p-Diox & 294 & 4.2 & 2.6 & 4.0 & 9 \\
\hline $\mathrm{NO}_{2}$ & $\mathrm{OMe}$ & p-Diox & 302 & 4.6 & 1.5 & 5.1 & 10 \\
\hline $\mathrm{NO}_{2}$ & $\mathrm{SMe}$ & p-Diox & 322 & 4.4 & 1.9 & 6.1 & 17 \\
\hline $\mathrm{NO}_{2}$ & $\mathrm{~N}_{2} \mathrm{H}_{3}$ & p-Diox & 366 & 6.3 & 1.8 & 7.6 & 9 \\
\hline $\mathrm{NO}_{2}$ & $\mathrm{NH}_{2}$ & Acetone & 365 & 6.2 & 1.7 & 9.2 & 15 \\
\hline $\mathrm{NO}_{2}$ & $\mathrm{NMe}_{2}$ & Acetone & 376 & 6.4 & 2.2 & 12 & 28 \\
\hline \multicolumn{8}{|l|}{ Ortho- } \\
\hline $\mathrm{NO}_{2}$ & $\mathrm{Me}$ & Neat & & 3.9 & 1.6 & 1.0 & 6 \\
\hline $\mathrm{NO}_{2}$ & $\mathrm{Br}$ & p-Diox & & 4.0 & 1.8 & 0.4 & 7 \\
\hline $\mathrm{NO}_{2}$ & $\mathrm{OH}$ & p-Diox & 348 & 3.4 & 1.5 & 1.2 & 3 \\
\hline $\mathrm{NO}_{2}$ & $\mathrm{OMe}$ & Neat & 318 & 3.8 & 1.7 & 1.4 & 6 \\
\hline $\mathrm{NO}_{2}$ & $\mathrm{NH}_{2}$ & p-Diox & & 4.1 & 1.6 & 2.5 & 8 \\
\hline \multicolumn{8}{|l|}{ Meta- } \\
\hline $\mathrm{NO}_{2}$ & $\mathrm{Me}$ & Neat & & 3.9 & 1.6 & 1.5 & 6 \\
\hline $\mathrm{NO}_{2}$ & $\mathrm{Br}$ & p-Diox & & 3.4 & 1.7 & 1.0 & 5 \\
\hline $\mathrm{NO}_{2}$ & $\mathrm{OH}$ & p-Diox & & 3.6 & 1.3 & 0.8 & 6 \\
\hline $\mathrm{NO}_{2}$ & $\mathrm{OMe}$ & p-Diox & 326 & 3.9 & 1.7 & 1.6 & 5 \\
\hline $\mathrm{NO}_{2}$ & $\mathrm{NH}_{2}$ & p-Diox & 396 & 4.7 & 1.5 & 1.9 & 7 \\
\hline
\end{tabular}

in most cases their $\beta$ values are even less than the sum values of their monosubstituted derivatives (see Table 2). Also, ortho substituted derivatives are not always superier to the meta derivatives, contrary to expectations based on resonance structures. For the nitroanilines, whose amino nitrogens are properly hybridized, one finds para $\gg>0$ ohro > meta as expected. However, for the other donors, as a result of their $\mathrm{sp}^{3}$ centers, their electron donating mechanisms are less clear. In the case of the methyl group, whose donating strength is thought to be a result of hyperconjugation, the $\beta$ values for the different substitution patterns are found to be quite comparable with para $>$ meta $>\approx$ ortho.

If low lying charge-transfer excitations are responsible for the large nonlinearities in para donor-acceptor substituted benzenes, there should be a trade-off between nonlinearity and transparency. To explore this question, we have characterized a wide range of donor-acceptor para-substituted benzenes, including the highly colored dicyanovinyl and tricyanovinyl derivatives and the transparent cyano and aldehyde derivatives. Measurement results for $\beta$ and the wavelength of the intense lowest energy transitions are shown in a logarithmic plot in Fig. 2 . The good correlation between $\beta$ and $\lambda_{\max }$ confirms that such a trade-off exists, at least in benzenes. Since measurements are made with $1.91 \mu \mathrm{m}$ radiation, such an increase is not the result of dispersive enhancement above the hypothetical zero-frequency 
Table 3: Results on para disubstituted benzenes.

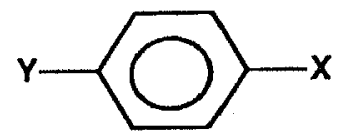

$\mathrm{X} \quad \mathrm{Y} \quad \lambda_{\max } \quad \mu 10^{-18} \quad \alpha 10^{-23} \quad \beta 10^{-30} \quad \gamma 10^{-36}($ esu $)$

\begin{tabular}{llllllll}
\hline $\mathrm{CN}$ & $\mathrm{Me}$ & Neat & & 4.4 & 1.5 & 0.7 & 5 \\
$\mathrm{CN}$ & $\mathrm{Cl}$ & p-Diox & & 2.3 & 1.6 & 1.4 & 4 \\
$\mathrm{CN}$ & $\mathrm{OPh}$ & p-Diox & & 4.1 & 2.6 & 1.2 & 9 \\
$\mathrm{CN}$ & $\mathrm{OMe}$ & p-Diox & 248 & 4.8 & 1.7 & 1.9 & 4 \\
$\mathrm{CN}$ & $\mathrm{SMe}$ & p-Diox & & 4.4 & 2.0 & 2.8 & 9 \\
$\mathrm{CN}$ & $\mathrm{NH}_{2}$ & p-Diox & 270 & 5.0 & 1.6 & 3.1 & 6 \\
$\mathrm{CN}$ & $\mathrm{NMe}_{2}$ & p-Diox & 290 & 5.6 & 2.1 & 5.0 & 10 \\
$\mathrm{COH}$ & $\mathrm{Me}$ & Neat & & 3.0 & 1.6 & 1.7 & 7 \\
$\mathrm{COH}$ & $\mathrm{OPh}$ & Neat & 269 & 2.8 & 2.5 & 1.9 & 12 \\
$\mathrm{COH}$ & $\mathrm{OMe}$ & Neat & 269 & 3.5 & 1.7 & 2.2 & 8 \\
$\mathrm{COH}$ & $\mathrm{SMe}$ & Neat & 310 & 3.1 & 1.9 & 2.6 & 13 \\
$\mathrm{COH}$ & $\mathrm{NMe}_{2}$ & p-Diox & 326 & 5.1 & 2.0 & 6.3 & 18 \\
$\mathrm{NO}$ & $\mathrm{NMe}_{2}$ & p-Diox & 407 & 6.2 & 2.1 & 12 & - \\
$\mathrm{CHC}(\mathrm{CN})_{2}$ & $\mathrm{OMe}$ & p-Diox & 345 & 5.5 & 2.4 & 9.8 & 30 \\
$\mathrm{CHC}(\mathrm{CN})_{2}$ & $\mathrm{Jullolidine}$ & $\mathrm{CH}_{2} \mathrm{Cl}_{2}$ & 458 & 7.5 & 3.0 & 22 & - \\
$\mathrm{C}_{2}(\mathrm{CN})_{3}$ & $\mathrm{NH}_{2}$ & $\mathrm{CH}_{2} \mathrm{Cl}_{2}$ & 498 & 7.8 & 3.4 & 23 & - \\
$\mathrm{C}_{2}(\mathrm{CN})_{3}$ & $\mathrm{NMe}_{2}$ & $\mathrm{CH}_{2} \mathrm{Cl}_{2}$ & 516 & 8.0 & 3.7 & 30 & - \\
$\mathrm{C}_{2}(\mathrm{CN})_{3}$ & Julolidine & $\mathrm{CH}_{2} \mathrm{Cl}_{2}$ & 556 & 8.5 & 3.9 & 36 & - \\
\hline
\end{tabular}

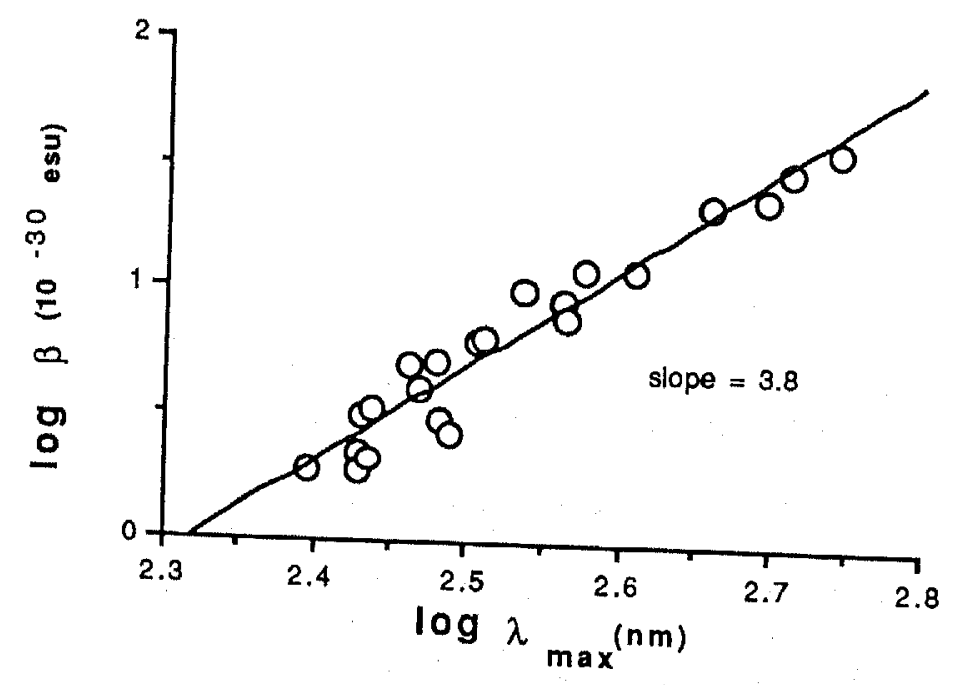

Figure 2, Logarithmic plot of $\beta$ vs $\lambda_{\max }$ for p-disubstituted benzenes 
electronic $\beta$ due to the finite frequency of the experimental fundamental. The question then is whether the widely quoted two-state model can account for this clearly observed correlation. It states that, for long-axis polarizations, $\beta \propto$ $\left(\lambda_{\max }\right)^{3} \mathrm{f} \Delta \mu$, the product of cubed wavelength with the oscillator strength and difference of Franck-Condon-state dipole moments. There is no known systematic dependence of $f$ and $\Delta \mu$ on $\lambda_{\max }$, therefore critical assessment of the two-level model awaits further spectroscopic and solvatochromic measurements. One might expect $f$ and $\Delta \mu$ within this class of weakly polarized molecules to be correlated with the combined donor-acceptor strength, which factor might also increase $\lambda_{\max }$. Allowing for some unidentified positive correlation which is here approximated as $\mathrm{f} \Delta \mu \propto$ $\left(\lambda_{\max }\right)^{m}$ with $\mathrm{m} \geq-1$ (since $\left.\mathrm{f} \propto \mu_{\mathrm{ge}}{ }^{2} \lambda\right)$ the two-state model predicts $\beta \propto\left(\lambda_{\max }\right)^{\mathrm{n}}, \mathrm{n}=3+\mathrm{m}$. However, oscillator strengths of these bands have been measured and exhibit no direct correlation with wavelength, typically varying between 0.3 and 0.7 , thus requiring that $m \geq 0, n \geq 3$. This prediction is in agreement with the data of Fig. 2 which shows that, within the uncertainty of some dispersion enhancement for the high $\lambda_{\max }$ data, a near quartic variation of $\beta$ with $\lambda_{\max }$ occurs. Therefore it appears that the simple two-state model is adequate when applied to a restricted class of compounds, benzene derivatives in this case, where structural modifications are directed at the charge transfer bands and the hyperpolarizabilities.

\section{Conjugation}

The effects of conjugation length, linkage, and planarity on nonlinear polarizabilities are investigated by examining 4,4'- disubstituted biphenyls, diphenylacetylenes, trans-stilbenes, diphenylfurans, and other phenyl-phenylvinylenes. Measurement results for the $4^{\prime}$-methoxy-4-nitro derivatives are given in Table 4 (complete results will be given in a later publication). Two of the values in Table 4 are estimated from measurement results on compounds of similar structures. The $\beta$ value of the biphenyl derivative is estimated from that of 4'-butoxy-4-nitrobiphenyl and the value for phenylvinylenestilbene derivative is estimated from a comparison of values obtained for

Table 4: Results on various 4-methoxy-4'-nitroarenes.

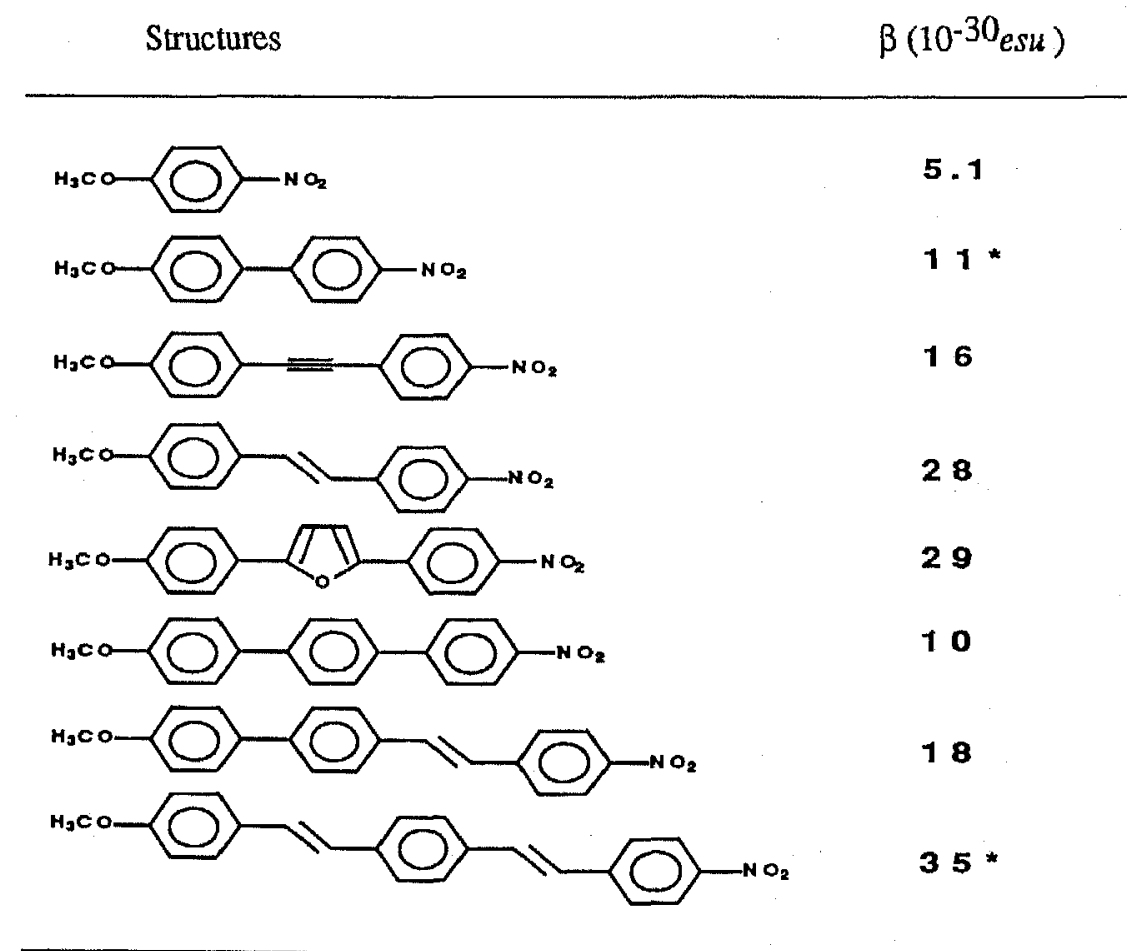

* See text. 
4'-dimethylamino-4-nitro-trans-stilbene and its longer analogue as well as from other donor-acceptor substituted stilbene and phenylvinylenestilbene derivatives. Measurements on the methoxy substituted compounds are currently underway.

As a result of the extended conjugation, the biphenyl derivatives are found to give higher $\beta$ values than their benzene analogues. The extent of enhancement however depends on the strength of the donor and acceptor groups. Since the phenyl rings are free to rotate, breaking up the conjugation pathway for electron transfer, the biphenyl structure cannot be very effective for optical nonlinearity. However, the degree of planarity is expected to depend on the electron donating and accepting strength of the substituents. With strong resonance donors such as amine and dimethylamine, substantial double bond character may be imposed on the $\sigma$ linkage of biphenyl, leading to a more planar structure in solution and higher molecular nonlinearity. Such an expectation is collaborated by our measurements on amine and dimethylamine biphenyl derivatives whose enhancement in $\beta$ is larger than that found in methyl or bromo derivatives.

Further enhancement is realized with diphenylacetylene conjugation. The diphenylacetylene structure is both longer and more planar than biphenyl but only moderate increase of hyperpolarizability is observed. The difference between diphenylacetylene and trans-stilbene derivatives is even more striking considering the similarity of the two structures.

Table 5: Results on mono and 4-4'-disubstituted stilbenes

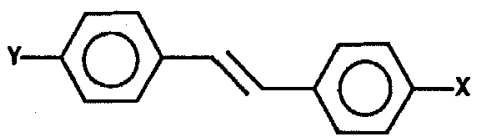

\begin{tabular}{|c|c|c|c|c|c|c|c|}
\hline$X$ & $\mathrm{Y}$ & solvent & $\lambda_{\max }$ & $\mu 10^{-18}$ & $\alpha 10^{-23}$ & $\beta 10^{-30}$ & $\gamma 10^{-36}(e s u)$ \\
\hline H-Trans & $\mathrm{H}$ & $\mathrm{CHCl}_{3}$ & 300 & 0.0 & 2.8 & 0.0 & 26 \\
\hline $\begin{array}{l}\mathrm{H}--\mathrm{Cis} \\
\mathrm{NH}_{2}\end{array}$ & $\begin{array}{l}\mathrm{H} \\
\mathrm{H}\end{array}$ & $\begin{array}{l}\text { Neat } \\
\text { p-Diox }\end{array}$ & $\begin{array}{l}300 \\
332\end{array}$ & $\begin{array}{l}0.0 \\
2.2\end{array}$ & $\begin{array}{l}2.6 \\
3.1\end{array}$ & $\begin{array}{l}0.0 \\
6.5\end{array}$ & $\begin{array}{l}12 \\
28\end{array}$ \\
\hline $\mathrm{NMc}_{2}$ & $\mathrm{H}$ & p-Diox & 340 & 2.2 & 3.6 & 10 & 59 \\
\hline $\mathrm{NO}_{2}$ & $\mathrm{H}$ & p-Diox & 345 & 4.7 & 3.2 & 9.1 & 55 \\
\hline $\mathrm{NO}_{2}$ & $\mathrm{Me}$ & p-Diox & 351 & 4.7 & 3.5 & 15 & 77 \\
\hline $\mathrm{NO}_{2}$ & $\mathrm{OH}$ & p-Diox & 370 & 5.5 & 3.3 & 17 & 104 \\
\hline $\mathrm{NO}_{2}$ & $\mathrm{OPh}$ & p-Diox & 350 & 4.6 & 4.2 & 18 & 80 \\
\hline $\mathrm{NO}_{2}$ & $\mathrm{OMe}$ & p-Diox & 364 & 4.5 & 3.4 & 28 & 79 \\
\hline $\mathrm{NO}_{2}$ & $\mathrm{SMe}$ & p-Diox & 374 & 4.3 & 3.9 & 26 & 113 \\
\hline $\mathrm{NO}_{2}$ & $\mathrm{NH}_{2}$ & $\mathrm{CHCl}_{3}$ & 402 & 5.1 & 3.2 & 40 & 147 \\
\hline$D 14-\mathrm{NO}_{2}$ & $\mathrm{~N}(\mathrm{Me})_{2}$ & $\mathrm{CHCl}_{3}$ & 424 & 6.2 & 3.4 & 83 & 225 \\
\hline $\mathrm{NO}_{2}$ & $\mathrm{Br}$ & p-Diox & 344 & 3.2 & 3.8 & 14 & 98 \\
\hline $\mathrm{NO}_{2}$ & COOMe & $\mathrm{CH}_{2} \mathrm{Cl}_{2}$ & 350 & 4.0 & 3.8 & 4.0 & 46 \\
\hline $\mathrm{NO}_{2}$ & $\mathrm{COH}$ & p-Diox & 352 & 4,1 & 3.5 & 6.0 & 57 \\
\hline $\begin{array}{l}\mathrm{CN} \\
\mathrm{CN}\end{array}$ & $\begin{array}{l}\mathrm{OH} \\
\mathrm{OMe}\end{array}$ & $\begin{array}{l}\text { p-Diox } \\
\text { p-Diox }\end{array}$ & $\begin{array}{l}344 \\
340\end{array}$ & $\begin{array}{l}4.5 \\
5.5\end{array}$ & $\begin{array}{l}3.2 \\
3.5\end{array}$ & $\begin{array}{l}13 \\
9.3\end{array}$ & $\begin{array}{l}52 \\
44\end{array}$ \\
\hline $\mathrm{CN}$ & $\mathrm{N}(\mathrm{Me})_{2}$ & $\mathrm{CHCl}_{3}$ & 382 & 5.7 & 3.9 & 36 & 125 \\
\hline $\mathrm{Br}$ & OMe & p-Diox & 325 & 4.0 & 3.4 & 2.5 & 54 \\
\hline
\end{tabular}


For a given set of donor and acceptor groups, the diphenylacetylenic compound is found to be much less nonlinear, with $\beta$ value about $50 \%$ lower than that of its trans-stilbene analogue. Since $\beta$ is a measure of the asymmetric polarizability between the two ends of these elongated molecules, it is unlikely that the difference in axial symmetry will lead to a substantial change in $\beta$ values. The difference in orbital hybridizations between the acetylenic and ethylenic linkages is however more significant. Although they are in plane with the phenyl $\pi$ orbitals which are $\mathrm{sp}^{2}$ hybridized, the $\mathrm{sp}^{1}$ hybridized acetylenic orbitals may interact less effectively with the phenyl orbitals, possibly resulting in a potential barrier between the two phenyl rings. Such a difference of course does not exit in the trans-stilbene structure allowing effective delocalization of all the $\pi$ electrons. Similar considerations will be used again later to account for the observed nonlinearity reduction resulting from azo or azomethine substitution at the ethylenic linkage of trans-stilbene derivatives.

The extended and planar structure makes trans-stilbene a very effective conjugated backbone. Among the conjugated structures included in the present study, the trans-stilbene derivatives are found to afford the highest volume normalized nonlinearity for a given set of donor and acceptor groups. Measurement results for monosubstituted and disubstituted nitro as well as disubstituted cyano stilbene derivatives are given in Table 5 . Between the benzene and stilbene structures, typical enhancement of 6 to 8 times is realized for the molecular hyperpolarizability. Such is the case even for the donor or acceptor monosubstituted derivatives. Only modest increases, typically less than 0.5 Debye, are seen for the ground state dipole moments. With the substantial increase in conjugation length, this indicates a decrease in the fractional charge formally transfered from the donor to the acceptor in the ground state. In addition, the charge-transfer bands of trans-stilbene derivatives are typically 50 to $60 \mathrm{~nm}$ red shifted in comparison to that of the benzenes. Analogous trade-off between nonlinearity and transparency is also observed. For a given $\lambda_{\max }$, however, substantially higher nonlinearity is offered by the stilbene derivatives. From a logarithmic plot of $\beta$ and $\lambda_{\max }$ as shown in Fig. 3 , it is evident that the hyperpolarizability of the stilbene system shows a much stronger dependence on the wavelength of the charge-transfer band than that of the benzene system. It is interesting to note that the thiomethyl donor, which is found to be significantly more effective than the methoxy group in the benzene system, is slightly less effective than the methoxy group in inducing asymmetric polarizability in the stilbene system. Since the hyperpolarizability of the longer stilbene system is dominated by resonance interaction between donor and acceptor, the lack of propensity for the sulfur atom (and other 2nd row elements) to form double bonded resonance structure may result in the reduced effectiveness of the thiomethyl donor.

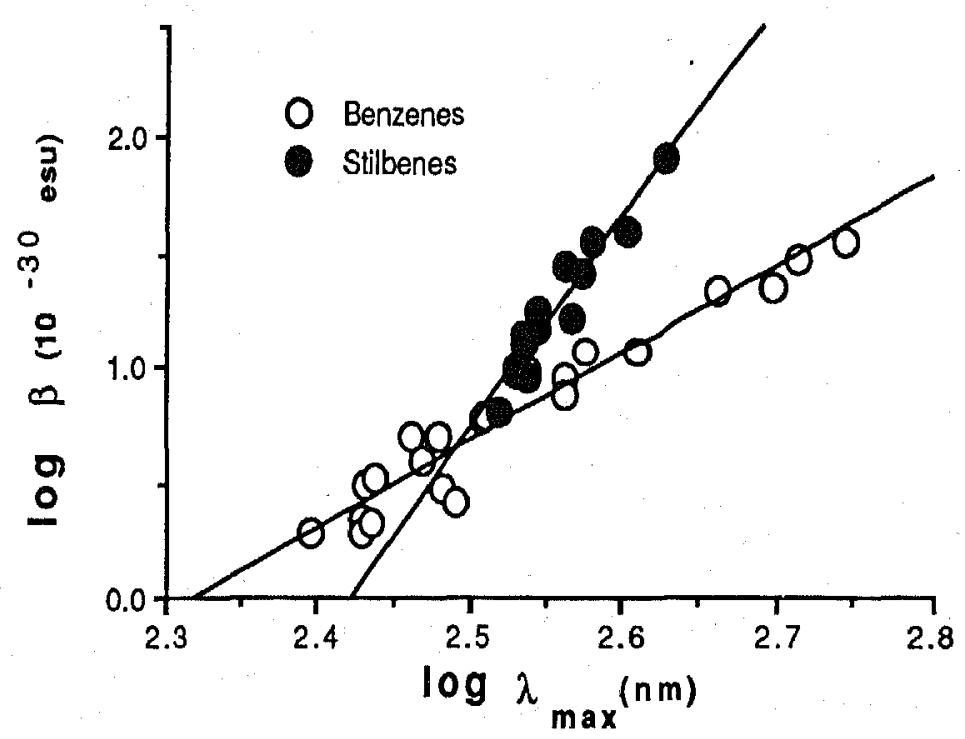

Figure 3. Logarithmic plot of $\beta$ vs $\lambda_{\max }$ for p-disubstituted benzenes and 4-4'-disubstituted stilbenes 
Again the above observations on the stilbene derivatives can be used to qualitatively assess the validity of the two-state model; and the reliability of using linear optical measurements, such as absorption spectroscopy and solvatochomic effect, to calculate the hyperpolarizabilities of compounds with different structures. According to the two-state model, since the oscillator strengths of the benzene and stilbene derivatives do not vary by more than a factor of two and do not correlate with $\lambda_{\max }$, the larger values of $\beta$ and its strong dependence on $\lambda_{\max }$ for the stilbene derivatives would have to be attributed to a much larger and strongly varying $\Delta \mu$. Our solvatochromic measurements however reveal only a weakly varying $\Delta \mu$ for the stilbene system, increasing from 20 Debye for nitrostilbene to 28 Debye for 4-dimethylamino-4'-nitrostilbene. Therefore, for the stilbene system, the two-state model cannot account for the sharp increase of $\beta$ with increasing donor-acceptor strengths. When used to account for the difference between benzene and stilbene derivatives, the two-state model is also found to be inadequate. For instance, our solvatochromic measurements yield comparable values of oscillator strength and a factor of two increase in $\Delta \mu$ for the equally colored p-nitroaniline ( $\lambda_{\max }=365 \mathrm{~nm}, \mathrm{f}=0.3$, and $\Delta \mu=12 \mathrm{D}$ ) and 4-methoxy-4'-nitrostilbene ( $\lambda_{\max }=364 \mathrm{~nm}, \mathrm{f}=0.26$, and $\Delta \mu=24 \mathrm{D}$ ), leading to a two-state $\beta$ ratio of 1.7 . Their measured hyperpolarizabilities differ by a factor of 3.2 instead.

One may speculate that it is generally possible to obtain higher nonlinearity with longer conjugation. Examination of longer arene derivatives however shows otherwise. Substantial decrease of nonlinearity per unit length is found for the longer arene derivatives (see Table 4). Little enhancement is realized by the longer diphenylfuran derivative. This result is particularly surprising in light of the sharp increase in $\beta$ as a function of the number of double bonds reported on polyvinyl diphenyl derivatives ${ }^{9}$. Evidently, the cis conformation, the five member ring strain, and the ether bridge of the furan are all structural factors that influence molecular hyperpolarizability. In the case of terphenyl, nonplanarity must account for some of the decrease since the phenyl rings are free to rotate. Interestingly, its nonlinearity is three times less than that of the furan derivative which is structurally quite similar if the five member ring is considered to be aromatic due to the delocalization of one of the oxygen lone pairs. The modest $\beta$ of the expectedly planar phenylvinylene stilbene derivative is somewhat puzzling. Bond alternation, as a result of the intrinsic asymmetry of the end groups, may account for part of the decrease. This however cannot be the principle reason since no saturation effect is observed for the enhancement of $\beta$ with conjugation length for the polyvinyl diphenyl derivatives ${ }^{9}$ and push-pull polyenes 10 of comparable lengths. An important property of the conjugation structures given in Table 4 is that they are formally aromatic or made up of aromatic structures according to the $4 n+2$ rule. The consequence of effective charge transfer interaction includes the conjugation of the donor electron density, thus resulting in a significant deviation from the aromatic configuration. This apparent trade-off between charge transfer and aromaticity may help rationalize the rapid saturation of nonlinearity vs conjugation length for arene derivatives. In any case, enhancement of hyperpolarizability by way of extended conjugation appears to be a subtle endeavor and cannot be easily generalized.

\section{Substitution Effects}

There is very little information available on how molecular substitutions, intended to influence other material properties such as transparency, solubility, cystal packing, and chemically convenient functionality for incorporation into polymeric structures, will affect the hyperpolarizability. We address this issue by examining the effects of heteroatom and electron donating or withdrawing side-group substitutions in the benzene and stilbene systems. Our measurement results are tabulated in Table 6. Our observations can be summarized as follows: although the substitution effects on the absorption band largely obey Dewar's rules, their effects on $\beta$ are mostly deterimental and cannot be accounted for by dispersive considerations due to the substitution induced shift of the absorption bands. In particular, aza substitutions on the 2 or 3 position of para disubstituted benzene derivatives and azo or azomethine substitutions on 4,4 disubstituted stilbene derivatives are very damaging, reducing the $\beta$ value by as much as $80 \%$. The effects of side-group substitutions with weak electron acceptor such as fluorine and cyano are also quite severe while only minor reductions are observed with electron donors such as methyl and methoxy groups. 
The only exception to this decreasing trend is provided by 2',4'-dimethoxy-4-nitrostilbene which shows a $20 \%$ increase in $\mu \beta$ product over the 4-4'-disubstituted derivative. This increase may be a result of the combined contributions from two donating groups whose substitution positions allow transfer of electron densities from both donors to the accepting group through charge seperated resonance structures. Such arguements will predict an enhancement of nonlinearity for 4'-methoxy-2,4-dinitrostilbene where two strong accepting groups act to polarize the charge distribution. Instead, a substantial (25\%) reduction in $\beta$ is observed with only slight increase in dipole

Table 6: Results on heteroatom and side-group substituted benzenes and stilbenes

\begin{tabular}{|c|c|c|c|c|c|c|}
\hline Substitution & solvent & $\lambda_{\max }^{6}$ & $\mu 10^{-18}$ & $\alpha 10^{-23}$ & $\beta 10^{-30}$ & $\gamma 10^{-36}($ esu $)$ \\
\hline $3, \mathrm{Aza} ; 4, \mathrm{NH}_{2}$ & Acetone & & 6.5 & 1.7 & 3.7 & 11 \\
\hline $\begin{array}{l}\text { 2,Aza; } 4, \mathrm{OMe} \\
3, \mathrm{Me} ; 4, \mathrm{NH}_{2}\end{array}$ & $\begin{array}{l}\text { p-Diox } \\
\text { p-Diox }\end{array}$ & & $\begin{array}{l}3.5 \\
6.2\end{array}$ & $\begin{array}{l}1.5 \\
1.9\end{array}$ & $\begin{array}{l}2.2 \\
8.7\end{array}$ & $\begin{array}{l}10 \\
17\end{array}$ \\
\hline $2, \mathrm{Cl} ; 4, \mathrm{NH}_{2}$ & p-Diox & 350 & 5.9 & 1.8 & 6.8 & 12 \\
\hline $3, \mathrm{OMe} ; 4, \mathrm{NH}_{2}$ & p-Diox & & 6.0 & 1.8 & 8.7 & 19 \\
\hline $2, \mathrm{~F} ; 4, \mathrm{OMe}$ & p-Diox & 304 & 4.4 & 1.8 & 2.5 & 10 \\
\hline $2,5, \mathrm{~F} ; 4, \mathrm{OMe}$ & p-Diox & 304 & 4.9 & 1.8 & 2.6 & 12 \\
\hline $2,3,5,6, F ; 4, \mathrm{OMe}$ & p-Diox & 270 & 4.2 & 1.8 & 1.7 & 7 \\
\hline
\end{tabular}

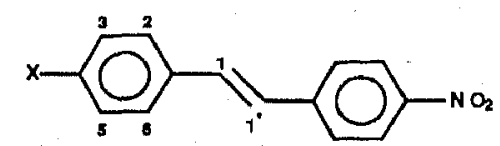
$\mathrm{X}$
Substitution
solvent
$\lambda_{\max }$
ب $10^{-18}$
$\alpha 10^{-23}$
$\beta 10^{-30} \quad \gamma 10^{-36}(\mathrm{esu})$

\begin{tabular}{|c|c|c|c|c|c|c|c|}
\hline $\mathrm{H}$ & 1,Aza & p-Diox & 346 & 4.4 & 2.7 & 4.9 & 26 \\
\hline $\mathrm{Me}$ & 1,Aza & p-Diox & 351 & 4.7 & 3.5 & 15 & 77 \\
\hline $\mathrm{OMe}$ & 1,Aza & p-Diox & 376 & 4.4 & 3.3 & 14 & 76 \\
\hline OMe & 1'Aza & p-Diox & 349 & 5.4 & 2.5 & 6.6 & 30 \\
\hline $\mathrm{NH}_{2}$ & 1,1',Azo & p-Diox & 420 & 5.8 & 3.5 & 29 & 170 \\
\hline NEtEtOH & 1,1',Azo & p-Diox & 455 & 6.0 & 3.8 & 32 & 190 \\
\hline $\mathrm{OMe}$ & $3, \mathrm{Me}$ & p-Diox & 366 & 5.2 & 3.7 & 26 & 96 \\
\hline $\mathrm{OMe}$ & $3, \mathrm{OMe}$ & p-Diox & 380 & 4.7 & 3.7 & 23 & 117 \\
\hline $\mathrm{OMe}$ & $3, F$ & p-Diox & 363 & 4.1 & 3.4 & 18 & 92 \\
\hline $\mathrm{OMe}$ & $2, \mathrm{OMe}$ & p-Diox & 395 & 4.8 & 3.9 & 32 & 11 \\
\hline $\mathrm{OMe}$ & $1^{\prime}, \mathrm{CN}$ & p-Diox & 361 & 5.3 & 3.8 & 21 & 86 \\
\hline $\mathrm{Br}$ & $1, \mathrm{CN}$ & p-Diox & 340 & 4.6 & 2.9 & 8.0 & 30 \\
\hline $\mathrm{Br}$ & $1, \mathrm{Aza} ; 1, \mathrm{CN}$ & p-Diox & 382 & 4.1 & 3.6 & 2.1 & 59 \\
\hline $\mathrm{OMe}$ & $2^{\prime}, \mathrm{NO}_{2}$ & p-Diox & 390 & 4.7 & 3.7 & 22 & 110 \\
\hline
\end{tabular}


moment. Since only one ortho substituent is present in either compound, steric hindrance, which may lead to nonplanarity and reduced nonlinearity, should be minimal. The observed spectral red shift supports such a contention. The reduction in nonlinearity for the dinitro compound therefore is an indication that the "resonance structure" picture of charge transfer, where charge migrates from the donor through the conjugation to the acceptor, is an over-simplification. Polarization of the conjugation electrons must also be important and such polarization may have a saturable limit, allowing cooperative contributions for weak donors but not for strong acceptors.

Substituents which lower molecular symmetry can clearly have an effect on the hyperpolarizability, which depends ultimately on the molecular electronic structure. Such an effect is expected to be small for substitutent which does not greatly alter the effective symmetry of the $\pi$ system. 2-methyl substitution of p-nitroaniline may be such an example. The effect of 3-methyl, 3-methoxy, or ethylenic cyano substitutions on 4-methoxy-4'-nitrostilbene cannot be a result of symmetry changes since the parent molecule does not possess a symmetry axis. The substitution effects on the conjugation must be considered. Perhaps, our observation of a rather general reduction of hyperpolarizability resulting from heteroatom as well as side-group substitutions can be rationalized by realizing that the effectiveness of the benzene and stilbene conjugations arise from their aromaticities which offer properties such as planarity and bond equivalence. Any substitution which reduces bond equivalence, by altering the bond length, electronegativity, or hybridization of the substituted site, will lead to less effective delocalization hence reduced nonlinearity. Thus, drastic perturbations of the conjugation such as aza and perfluoro substitutions on benzene derivatives and azo and azomethine substitution for stilbene derivatives result in significantly lower $\beta$ values. This view is supported by measurement results on diphenylacetylene derivatives (see Table 4). As discussed earlier, the differences in bond length and hybridization between the acetylenic carbons and the phenyl carbons lead to a $40 \%$ reduction of hyperpolarizabilty in comparison to the stilbene derivatives.

\section{CONCLUSION}

We have systematically investigated the hyperpolarizabilities of benzene, stilbene, and other arene derivatives using EFTSH and THG measurements at $1.91 \mu \mathrm{m}$. A wide range of donor and acceptor groups were studied and their relative effectiveness in inducing asymmetric polarizabilities established. The trade-off of nonlinearity vs transparency was examined and an empirical quartic dependence established for the benzene derivatives. Such a dependence is compatible with the widely used two-state model. For the stilbene derivatives, a much sharper variation of hyperpolarizability with charge-transfer band wavelength is revealed. Solvatochromic and absorption measurements establish the inadequacy of the two-state model for the stilbene system. Different conjugations including biphenyls, diphenylacetylenes, and other longer arenes were studied. Issues concerning their planarity, length, and aromaticity were discussed. Enhancement of quadratic nonlinearity by way of increasing conjugation length is found to be ineffective for arene derivatives. Measurements of heteroatom and side-group substituted benzene and stilbene derivatives revealed a general reduction of the hyperpolarizability as a result of substitution. Such detrimental substitution effects are believed to be a result of the aromatic character of the arene conjugated structures.

\section{REFERENCES}

1. J. F. Nicoud and R. J. Twieg, in "Nonlinear Optical Properties of Organic Molecules and Crystals", edited by D. S. Chemla and J. Zyss, Vol 2 ( Academic Press, NY, 1987) 255

2. S. H. Stevenson, in preparation.

3. See for example C. J. F. Bottcher, "Theory of Electric Polarization", 2nd ed. (Elsevier, NY, 1973)

4. K. D. Singer and A. F. Garito, J. Chem. Phys. 75 (1981) 3572

5. G. R. Meredith B. Buchalter and C. Hanzlik, J. Chem. Phys. 78 (1983) 1533

6. G. R. Meredith, Optics Comm., 39 (1981) 89

7. B. Buchalter and G. R. Meredith, Appl. Optics, 21 (1982) 3221

8. G. R. Meredith, Chem. Phy. Lett., 92 (1982) 165

9. R. A. Huijts and G. L. J. Hesselink, Chem. Phys. Lett., 156 (1989) 209

10. M. Barzoukas, M. Blanchard-Desce, D. Josse, J.-M. Lehn, and J. Zyss, Chem. Phys., 133 (1989) 323 